\title{
Vaginal Sarcoma
}

National Cancer Institute

\section{Source}

National Cancer Institute. Vaginal Sarcoma. NCI Thesaurus. Code C7737.

A malignant mesenchymal neoplasm that arises from the vagina. Representative

examples include botryoid-type embryonal rhabdomyosarcoma, leiomyosarcoma, and endometrioid stromal sarcoma. 